\title{
First-Line Selective Internal Radiation Therapy in Patients with Uveal Melanoma Metastatic to the Liver
}

\author{
Alexandre Ponti ${ }^{1}$, Alban Denys ${ }^{1}$, Antonia Digklia ${ }^{2}$, Niklaus Schaefer ${ }^{3}$, Arnaud Hocquelet ${ }^{1}$, Jean-François Knebel ${ }^{4}$, \\ Olivier Michielin ${ }^{2}$, Clarisse Dromain ${ }^{1}$, and Rafael Duran ${ }^{1}$ \\ ${ }^{I}$ Department of Radiology and Interventional Radiology, Lausanne University Hospital, University of Lausanne, Lausanne, \\ Switzerland; ${ }^{2}$ Department of Medical Oncology, Lausanne University Hospital, University of Lausanne, Lausanne, Switzerland; \\ ${ }^{3}$ Department of Nuclear Medicine and Molecular Imaging, Lausanne University Hospital, University of Lausanne, Lausanne, \\ Switzerland; and ${ }^{4}$ Centre for Biomedical Imaging, Lausanne University Hospital, University of Lausanne, Lausanne, Switzerland
}

Survival of patients with uveal melanoma metastatic to the liver correlates strongly with disease control in the liver. Unfortunately, there are no standardized treatments for this chemoresistant disease. Selective internal radiation therapy (SIRT) has been tested as salvage therapy, but no data exist about its use as firstline therapy. The purpose of this study was to investigate the safety and efficacy of SIRT as first-line therapy in patients with uveal melanoma metastatic to the liver. Methods: This retrospective analysis of a prospectively collected cohort included 22 patients treated with first-line SIRT. Biochemical and clinical toxicities were recorded. Tumor response was determined according to the European Association for the Study of Liver Disease (EASL) criteria. Predictive factors of survival were analyzed by univariate and multivariate analysis. Overall survival was calculated using the Kaplan-Meier method with the log-rank test. Results: Grade 3-4 biologic and clinical toxicities occurred in $24 \%$ of patients (for both). According to the EASL criteria, disease control at 6 mo after SIRT was achieved in $15(52 \%)$ of the 29 SIRT patients and was predictive of survival. Median overall survival from the first SIRT was 18 mo (95\% confidence interval [95\% Cl], $8-28 \mathrm{mo})$. At the time of the analysis, 5 patients $(23 \%)$ were still alive. In multivariate analysis, largest lesion size (hazard ratio $[\mathrm{HR}], 1.22 ; 95 \% \mathrm{Cl}, 0.98-1.53$ ], liver tumor volume $(\mathrm{HR}$, $1.002 ; 95 \% \mathrm{Cl}, 1.0004-1.003)$, subsequent systemic therapy (HR, $0.04 ; 95 \% \mathrm{Cl}, 0.006-0.24$ ), and liver-directed locoregional therapy $(\mathrm{HR}, 0.204 ; 95 \% \mathrm{Cl}, 0.04-0.94)$ were predictive of survival. Conclusion: First-line SIRT is safe and produced promising outcomes in patients with uveal melanoma metastatic to the liver. Subsequent systemic and liver-directed locoregional therapies ameliorated survival, highlighting the potential for improved outcomes with combination approaches. The results of this study suggest that prospective trials using first-line SIRT should be considered.

Key Words: uveal melanoma; radioembolization; SIRT; tumor response; overall survival

J Nucl Med 2020; 61:350-356

DOI: 10.2967/jnumed.119.230870

\footnotetext{
Received May 6, 2019; revision accepted Aug. 5, 2019.

For correspondence or reprints contact: Rafael Duran, Department of Radiology and Interventional Radiology, Centre Hospitalier Universitaire Vaudois (CHUV), Rue du Bugnon 46, 1011 Lausanne, Switzerland.

E-mail: rafael.duran@chuv.ch

Published online Sep. 3, 2019.

COPYRIGHT @ 2020 by the Society of Nuclear Medicine and Molecular Imaging.
}

$\mathbf{U}$ veal melanoma is a rare disease, with an incidence of 5.1 per million in the United States, but constitutes the most common primary intraocular malignant tumor in adults. The 5-y survival rate is approximately $80 \%$ (1). However, $10 \%-30 \%$ of patients with uveal melanoma will develop systemic metastases within $5 \mathrm{y}$ and up to $45 \%$ within $15 \mathrm{y}$, predominantly in the liver (70\%-90\% of cases) (2,3). After diagnosis of metastases, the prognosis is greatly reduced, with a median overall survival (OS) of only 2 mo without treatment and 6-13 mo with treatment $(2,4)$. Therefore, patient survival strongly correlates with hepatic tumor control.

Although local eye treatments (proton beam, plaque brachytherapy) of the primary tumor are generally successful in eliminating cancer tissue and preventing local recurrence, there are no effective systemic therapies for metastatic uveal melanoma (5). Because patient prognosis is highly dependent on progression of liver metastases, various liver-directed locoregional treatments have been tested with the goal of extending survival. Despite encouraging results, surgery or local ablations are only rarely performed because most patients develop widespread liver metastases. Thus, treatments capable of covering the whole liver, such as transarterial chemoembolization, isolated hepatic perfusion, and selective internal radiation therapy (SIRT) — also called ${ }^{90} \mathrm{Y}$ radioembolization—are usually performed (6).

The scientific rationale for SIRT is 2-fold. SIRT consists of the administration of ${ }^{90} \mathrm{Y}$ microspheres into the hepatic artery. Because liver metastases receive their blood supply mainly from neovessels arising from the hepatic artery, administered microspheres are preferentially trapped inside the tumor microvasculature, minimizing damage to the surrounding normal liver parenchyma (7). Moreover, uveal melanoma is a radiosensitive tumor as demonstrated by treatment success of the primary eye tumor; thus, SIRT holds significant promise in achieving meaningful results in the treatment of liver metastases. Few studies have reported the use of SIRT as salvage therapy in uveal melanoma patients with liver metastases $(8-14)$. SIRT proved to be safe in patients with liver-dominant disease, unresectable and refractory to other treatment modalities such as systemic chemotherapy, with a reported median OS ranging from 3.1 to $12.3 \mathrm{mo}$ (8-14).

The aim of our study was to investigate the safety and efficacy of SIRT as first-line therapy in patients with uveal melanoma metastatic to the liver. 


\section{MATERIALS AND METHODS}

This single-institution retrospective study of a prospectively collected patient cohort was approved by the Institutional Review Board. Informed consent was waived.

\section{Patient Population}

Twenty-nine consecutive patients were considered for SIRT for liver metastases of uveal melanoma between 2010 and 2017. Baseline extrahepatic metastases were not considered a contraindication, because survival is related to hepatic disease control $(2,15)$. All patients were discussed at our multidisciplinary liver tumor board and provided informed consent for the procedure.

Inclusion criteria included biopsy-proven liver metastases, Eastern Cooperative Oncology Group (ECOG) status of no more than 2, adequate liver function (bilirubin $\leq 2 \mathrm{mg} / \mathrm{dL}$ ), adequate hematologic function (granulocyte count $\geq 1.5 \times 10^{9} / \mathrm{L}$, platelets $\geq 50 \times 10^{9} / \mathrm{L}$ ), and adequate kidney function (creatinine $<2 \mathrm{mg} / \mathrm{dL}$ ) (16). Seven patients were excluded for the following reasons: previous systemic or liver-directed therapies $(n=2)$, absence of follow-up after SIRT $(n=3)$, estimated pulmonary shunt fraction higher than $20 \%(n=1)$, or rapidly progressive liver metastases and worsening of liver function during treatment planning, precluding SIRT $(n=1)$. Thus, the final study population included 22 patients.

\section{Patient Assessment and Toxicity Analysis}

The patients' medical history and imaging findings were assessed, and the patients received a physical examination. Baseline complete laboratory tests (including liver, kidney, and hematologic functions) and imaging (whole-body PET/CT, contrast-enhanced thoracoabdominal CT, and liver MRI) were performed. From these data, patient baseline characteristics were obtained. Patients were followed by clinical assessment, laboratory tests, and CT or MRI to assess treatment toxicity and tumor response. The advent of extrahepatic spread, if any, was recorded. Toxicity was assessed using the National Cancer Institute Common Terminology Criteria for Adverse Events (version 4.0).

\section{Treatment}

Preprocedure simulation angiography allowed embolization of nontarget extrahepatic vessels (when appropriate) followed by injection of ${ }^{99 \mathrm{~m} T c-m a c r o a g g r e g a t e d ~ a l b u m i n ~ i n ~ t h e ~ p r o p e r, ~ l e f t, ~ o r ~ r i g h t ~}$ hepatic artery depending on tumor distribution and treatment planning. SPECT/CT permitted us to quantify the tumor volume to be treated, the tumor-to-liver uptake ratio, and the pulmonary and systemic shunt fraction and to perform dosimetry planning. The tumor volume to be treated was also calculated by contouring the metastases on pretreatment imaging (liver MRI, CT, PET/CT, or SPECT/CT after 99mTc-macroaggregated albumin injection). Treatment with SIRT (TheraSphere [Biocompatibles] and SIR-Spheres [Sirtex Medical]) was performed in the weeks after the simulation angiography and on an outpatient basis $(16,17)$. The methods used for calculating the required activity for injection and the actual dose delivered (partition model) have been reported elsewhere (17-19). Depending on tumor distribution and vascular access, ${ }^{90} \mathrm{Y}$-microspheres were administered either to a single lobe or to the whole liver. In cases of bilobar disease and sequential lobar treatment, the contralateral side was treated 1-2 mo after the first treatment. Depending on subsequent imaging followup, patients with incompletely treated disease or progressive liver disease were retreated.

\section{Response Assessment}

MR and CT images were analyzed by 2 radiologists during the same session to ensure careful comparison between pre- and postSIRT findings. Any discrepancy was resolved in consensus. Up to 2 target liver lesions ( $\geq 1 \mathrm{~cm}$ ) were chosen per patient. The 2 largest target lesions were evaluated (20). Tumor response was evaluated by the World Health Organization (WHO) guidelines, RECIST, modified RECIST (mRECIST), and the European Association for the Study of Liver Disease (EASL) guidelines (21-24). Patients were classified as

TABLE 1

Baseline Characteristics

\begin{tabular}{|c|c|}
\hline Characteristic & Data \\
\hline Total patients $(n)$ & $22(100 \%)$ \\
\hline \multicolumn{2}{|l|}{$\operatorname{Sex}(n)$} \\
\hline Male & $11(50 \%)$ \\
\hline Female & $11(50 \%)$ \\
\hline \multicolumn{2}{|l|}{ Mean age (y) } \\
\hline All patients & 59 (range, 30-82) \\
\hline Female & 58 (range, 39-73) \\
\hline Male & 61 (range, 30-82) \\
\hline \multicolumn{2}{|l|}{ ECOG status $(n)$} \\
\hline 0 & $16(73 \%)$ \\
\hline 1 & $6(27 \%)$ \\
\hline $\begin{array}{l}\text { Time from diagnosis } \\
\text { of uveal melanoma } \\
\text { to liver metastases }\end{array}$ & \\
\hline
\end{tabular}

Mean $34.9(95 \% \mathrm{Cl}, 19.7-50.1)$

Median

19 (range, 0-144)

Time from diagnosis

of liver metastases

to first SIRT (mo)

Mean

$2.7(95 \% \mathrm{Cl}, 2.3-3.1)$

Median

3 (range, 1-5)

No. of patients with $4(18 \%)$

extrahepatic metastases before SIRT $(n)$

Liver tumor distribution ( $n$ ) Whole liver $20(91 \%)$

Unilobar $2(9 \%)$

Liver tumor volume $\left(\mathrm{cm}^{3}\right)$

Mean $\quad 318.1(95 \% \mathrm{Cl}, 82.6-553.6)$

Median

130 (range, 10-2,750)

Largest liver tumor (cm)

Mean

Median

$4.1(95 \% \mathrm{Cl}, 2.4-5.8)$

Number of liver

metastases $(n)$

0-10 $13(59 \%)$

$>11 \quad 9(41 \%)$

Tumor-to-liver uptake ratio*

Mean

Median

$4.0(95 \% \mathrm{Cl}, 3.1-4.9)$

SUV $_{\max }$

Mean

3.5 (range, 1-10)

Median

7.5 (95\% Cl, 5.6-9.4)

7.4 (range, 3.3-22.1)

*99mTc-macroaggregated albumin SPECT/CT. 
responders (complete or partial response) or nonresponders (stable or progressive disease) according to each set of tumor response criteria (20-24). Disease control rate was defined as partial response + complete response + stable disease.

\section{Statistical Analysis}

Statistical analysis was performed using Anaconda (version 2.7; Python Language Reference), the Python module lifelines, and Rpy2 to link Python with R (version 3.1.3; R Foundation for Statistical Computing). Data were summarized using descriptive statistics. OS, progression-free survival, and hepatic progression-free survival were calculated from the first SIRT until death or the last follow-up. Patients who were alive at the end of the study period were censored at that time. Survival times were analyzed by the Kaplan-Meier method, and differences were calculated using the log-rank test. Univariate and multivariate Cox proportional hazard ratio (HR) testing was performed to identify factors associated with survival. Factors with a $P$ value of less than 0.1 on univariate analysis were included in multivariate analysis. A $P$ value of less than 0.05 was considered significant.

\section{RESULTS}

\section{Patient Data}

Patient characteristics are summarized in Table 1 . The mean patient age was $59 \mathrm{y}$ (range, 30-82 y). Most patients had an ECOG status of $0(73 \%)$, bilobar disease $(91 \%)$, and no extrahepatic disease $(82 \%)$. The median diameter of the largest metastasis was $2.6 \mathrm{~cm}$ (range, 1.4-18.6 cm), and the median $\mathrm{SUV}_{\max }$ was 7.4 (range, $3.3-22.1$ ). Overall, $77 \%$ and $41 \%$ of the patients received systemic and liver-directed locoregional therapies after SIRT, respectively (Supplemental Table 1; supplemental materials are available at http://jnm.snmjournals.org). Seventeen patients (77\%) developed extrahepatic metastases after SIRT. The median follow-up period after the first SIRT was 15 mo (range, 1-65 mo).

\section{Treatment Data}

Treatment characteristics are summarized in Table 2. Twentynine SIRTs were performed (mean, 1.3 procedures per patient; range, 1-3). Fifteen patients $(68 \%)$ required prophylactic coil embolization. Most patients (73\%) underwent only 1 SIRT; $41 \%$ received whole-liver treatment in 1 session, $23 \%$ received fractioned whole-liver treatment (sequential right and left lobes), and $36 \%$ received only single-lobe treatment. Whole-liver SIRT was repeated in 1 patient. In 1 patient, bilobar treatment in 2 sessions was planned, but a celiac trunk dissection after right-liver SIRT prevented left-liver treatment. In another patient, activity and dose were calculated for whole-liver SIRT, but posttreatment SPECT/ CT showed only right-liver ${ }^{90} \mathrm{Y}$-microsphere deposition. In another patient, activity and dose were estimated for right-liver SIRT, but posttreatment SPECT/CT demonstrated whole-liver ${ }^{90} \mathrm{Y}-$ microsphere deposition (under treatment).

The activities and doses administered are shown in Table 2. The median activity infused per patient was $1.8 \mathrm{GBq}$. The median radiation doses to tumor, healthy liver, and lungs were 155.4, 46.2, and $1.1 \mathrm{~Gy}$, respectively.

\section{Toxicities}

Toxicities are summarized in Supplemental Table 2. Grade 1 and 2 clinical toxicities included mainly mild to moderate abdominal pain and fatigue (9 patients, 41\%). Grade 3 toxicities (7 patients, 32\%) included more severe abdominal pain requiring hospitalization ( 2 patients), radiation cholecystitis ( 3 patients), and clinical symptoms of liver failure (2 patients). There were no grade 4 clinical toxicities. Grade 3 and 4 laboratory perturbations
TABLE 2

Treatment Characteristics

\begin{tabular}{|c|c|}
\hline Characteristic & Data \\
\hline Total SIRT $(n)$ & $29(100 \%)$ \\
\hline \multicolumn{2}{|l|}{ SIRT per patient $(n)$} \\
\hline 1 & $16(73 \%)$ \\
\hline 2 & $5(23 \%)$ \\
\hline 3 & $1(5 \%)$ \\
\hline \multicolumn{2}{|l|}{ Liver treatment $(n)$} \\
\hline $\begin{array}{l}\text { Whole liver in } \\
\text { single session }\end{array}$ & $9(41 \%)$ \\
\hline $\begin{array}{l}\text { Whole liver in } \\
\text { multiple sessions }\end{array}$ & $5(23 \%)$ \\
\hline Lobar only & $8(36 \%)$ \\
\hline \multicolumn{2}{|l|}{$\begin{array}{l}\text { Sum of administered } \\
\text { activities per } \\
\text { patient (GBq) }\end{array}$} \\
\hline Mean & $2.1(95 \% \mathrm{Cl}, 1.7-2.5)$ \\
\hline Median & 1.8 (range, $1-2.8$ ) \\
\hline \multicolumn{2}{|l|}{$\begin{array}{l}\text { Mean administered } \\
\text { activity per } \\
\text { patient (GBq) }\end{array}$} \\
\hline Mean & $1.7(95 \% \mathrm{Cl}, 1.5-1.9)$ \\
\hline Median & 1.6 (range, $0.7-2.8$ ) \\
\hline \multicolumn{2}{|c|}{$\begin{array}{l}\text { Highest administered } \\
\text { activity per patient (GBq) }\end{array}$} \\
\hline Mean & $1.8(95 \% \mathrm{Cl}, 1.5-2.1)$ \\
\hline Median & 1.6 (range, $1-3$ ) \\
\hline \multicolumn{2}{|l|}{ Dose to tumor (Gy) } \\
\hline Mean & $171.7(95 \% \mathrm{Cl}, 142.5-200.9)$ \\
\hline Median & 155.4 (range, 43.9-356) \\
\hline \multicolumn{2}{|l|}{$\begin{array}{l}\text { Dose to healthy } \\
\text { liver (Gy) }\end{array}$} \\
\hline Mean & 50.4 (95\%Cl, 42.6-58.2) \\
\hline Median & 46.2 (range, 21-99.1) \\
\hline \multicolumn{2}{|l|}{ Dose to lungs (Gy) } \\
\hline Mean & $1.3(95 \% \mathrm{Cl}, 1.0-1.6)$ \\
\hline Median & 1.1 (range, 0.1-2.9) \\
\hline \multicolumn{2}{|l|}{$\begin{array}{l}\text { Type of } \\
{ }^{90} Y \text {-microspheres }(n)\end{array}$} \\
\hline TheraSphere & $5(23 \%)$ \\
\hline SIR-Spheres & 19 (86\%) \\
\hline Both & $2(9 \%)$ \\
\hline \multicolumn{2}{|l|}{$\begin{array}{l}\text { Post-SIRT systemic } \\
\text { therapies }(n)\end{array}$} \\
\hline Chemotherapy & $11(50 \%)$ \\
\hline Immunotherapy & 13 (59\%) \\
\hline Both & 7 (32\%) \\
\hline \multicolumn{2}{|l|}{$\begin{array}{l}\text { Post-SIRT locoregional } \\
\text { therapies }(n)\end{array}$} \\
\hline $\begin{array}{l}\text { Transarterial } \\
\text { chemoembolization }\end{array}$ & $4(18 \%)$ \\
\hline Thermal ablation & $5(23 \%)$ \\
\hline Both & $0(0 \%)$ \\
\hline
\end{tabular}


were observed in $4(18 \%)$ and $3(14 \%)$ patients, respectively. No difference in toxicity was noted between glass and resin microspheres. All patients with toxicity were treated conservatively with satisfactory evolution or were asymptomatic. There were no treatment-related deaths.

\section{Tumor Response and Survival Prediction}

Supplemental Table 3 summarizes tumor response. All response criteria categorized most patients as having stable disease at 3 mo after SIRT. However, the number of responders (partial and complete) increased at 6 mo. The absolute number of responders at 6 mo was higher for the mRECIST and EASL criteria $(47 \%$ and $58 \%$, respectively) than for the RECIST and WHO criteria (16\% and $26 \%$, respectively). None of the response criteria was predictive of survival at 3 mo after SIRT except for EASL, which was the only set of criteria that showed a significant difference between responders and nonresponders, with a median survival of 26 versus 11 mo, respectively (Table 3). At 6 mo after SIRT, mRECIST and EASL were able to accurately stratify patients as responders or nonresponders ( 27 vs. 11.5 mo and 26 vs. $11.5 \mathrm{mo}$, respectively) and were predictive of survival (both $P<0.05$, Table 3) (Fig. 1). Stratification of response by disease control rate was not discriminant at 3 mo for any of the response criteria (all: $P>0.05$ ), whereas EASL was the only set of criteria to accurately predict survival at 6 mo after therapy $(P=0.002$, Fig. 2$)$.

\section{Survival Outcomes}

At the time of the analysis, 17 patients $(77 \%)$ had died and 5 (23\%) were alive. Median OS after the diagnosis of liver metastases and after the first SIRT was 20 mo (95\% confidence interval [95\% CI], 11-31 mo) and $18 \mathrm{mo}$ (95\% CI, 8-28 mo), respectively. The median hepatic progression-free survival was $8 \mathrm{mo}(95 \% \mathrm{CI}, 5-26 \mathrm{mo})$, and overall progression-free survival was 5 mo (95\%CI, 2-17 mo).

Parameters used for univariate and multivariate analyses are reported in Table 4. In univariate analysis, liver tumor burden estimated by the largest lesion size (HR, 1.3; 95\% CI, 1.08-1.57), treated tumor volume (HR, 1.0008; 95\%CI, 1.0001-1.002), post-SIRT systemic therapy (HR, $0.33 ; 95 \%$ CI $0.12-0.86$ ), and liver-directed locoregional therapy (HR, $0.21 ; 95 \% \mathrm{CI}, 0.07-0.62)$ ) were significant predictors of survival (all: $P<0.05$ ), whereas ECOG status (HR, 2.73; 95\%CI, 0.88-8.44) showed a trend $(P=0.08)$. The mean activity administered per patient was omitted because of collinearity with the treated tumor volume, the latter being directly used to calculate the activity to be administered (17). All parameters other than ECOG $(P=0.38)$ remained significantly correlated with survival on multivariate analysis $(P<0.05)$ (Table 4$)$.

TABLE 3

Treatment Response Analysis

\begin{tabular}{|c|c|c|c|c|c|c|c|c|}
\hline \multirow[b]{2}{*}{ Criteria } & \multicolumn{4}{|c|}{$3 \mathrm{mo}$} & \multicolumn{4}{|c|}{$6 \mathrm{mo}$} \\
\hline & Survival (mo) & $\mathrm{HR}$ & $\mathrm{R}^{2}(\%)$ & $P$ & Survival (mo) & $\mathrm{HR}$ & $\mathrm{R}^{2}(\%)$ & $P$ \\
\hline RECIST & & 1 & - & - & & $0.27(0.03-2.08)$ & 13 & 0.207 \\
\hline $\mathrm{R}$ & - & & & & 26 & & & \\
\hline NR & 20 & & & & 22 & & & \\
\hline WHO & & $0.76(0.16-3.50)$ & 0 & 0.723 & & $0.47(0.13-1.76)$ & 8 & 0.264 \\
\hline $\mathrm{R}$ & 24 & & & & 26 & & & \\
\hline NR & 12 & & & & 18 & & & \\
\hline mRECIST & & $0.27(0.07-1.01)$ & 21 & 0.052 & & $0.15(0.04-0.60)$ & 40 & 0.007 \\
\hline $\mathrm{R}$ & 26 & & & & 27 & & & \\
\hline NR & 11.5 & & & & 11.5 & & & \\
\hline EASL & & $0.30(0.10-0.95)$ & 20 & 0.040 & & $0.22(0.07-0.75)$ & 29 & 0.016 \\
\hline $\mathrm{R}$ & 26 & & & & 26 & & & \\
\hline NR & 11 & & & & 11.5 & & & \\
\hline RECIST & & $0.16(0.02-1.65)$ & 8 & 0.124 & & $0.24(0.05-1.24)$ & 13 & 0.088 \\
\hline $\mathrm{DC}$ & 23 & & & & 25.5 & & & \\
\hline PD & 7.5 & & & & 14 & & & \\
\hline WHO & & $0.23(0.04-1.24)$ & 10 & 0.088 & & $0.24(0.05-1.24)$ & 13 & 0.088 \\
\hline $\mathrm{DC}$ & 24 & & & & 25.5 & & & \\
\hline PD & 8 & & & & 14 & & & \\
\hline mRECIST & & $0.22(0.04-1.15)$ & 12 & 0.072 & & $0.51(0.06-4.27)$ & 2 & 0.537 \\
\hline $\mathrm{DC}$ & 24 & & & & 25 & & & \\
\hline PD & 9.5 & & & & 22 & & & \\
\hline EASL & & $0.22(0.04-1.15)$ & 12 & 0.072 & & $0.07(0.01-0.56)$ & 27 & 0.011 \\
\hline $\mathrm{DC}$ & 24 & & & & 25.5 & & & \\
\hline PD & 9.5 & & & & 8.5 & & & \\
\hline $\begin{array}{l}\mathrm{R}=\text { respor } \\
\text { Data in par }\end{array}$ & $\begin{array}{l}\text { s; NR }=\text { nonr } \\
\text { heses are 95\% }\end{array}$ & onders; DC = dis & se contr & $P D=1$ & ressive diseas & & & \\
\hline
\end{tabular}




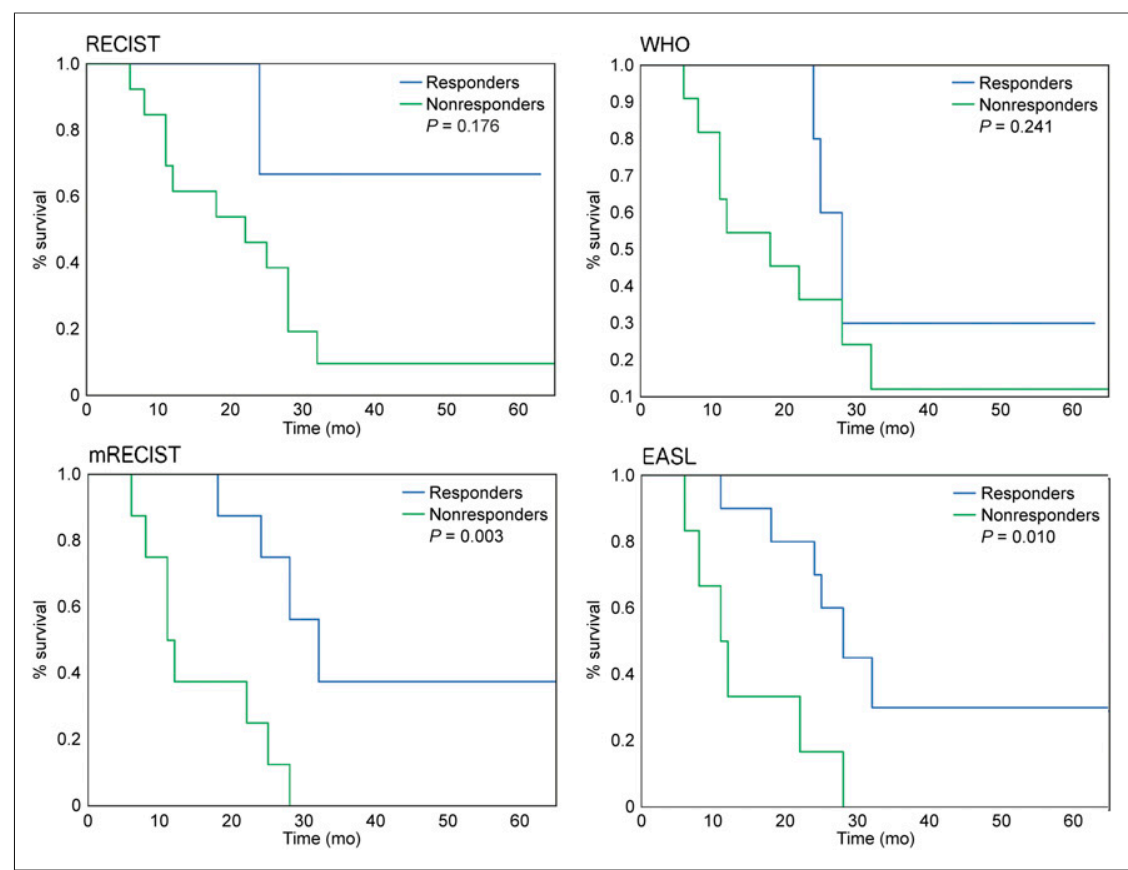

FIGURE 1. Survival analysis at 6 mo after SIRT.

\section{DISCUSSION}

The main finding of this study is that first-line SIRT is safe and demonstrates promising outcomes in patients with uveal melanoma metastatic to the liver.

Our complication rate (grade 3-4 clinical and laboratory toxicities observed in $32 \%$ of patients for both) may seem higher than in previous studies $(0 \%-25 \%)(8-13)$. A potential explanation is that we adopted a conservative methodology and reported toxicities at any time during the 6-mo period after SIRT and did not apply the 30-d cutoff used in many reports. Moreover, patients with preexisting laboratory toxicities were counted as having toxicities at follow-up, even if there was no change in grade. Furthermore, the seemingly higher complication rate could be attributed to the administered activity,

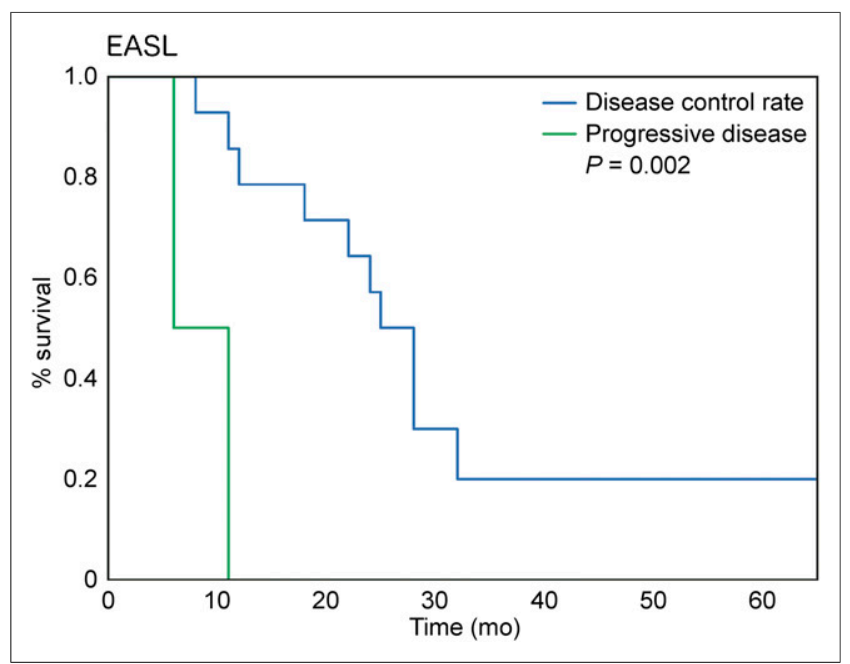

FIGURE 2. Survival analysis according to EASL response criteria when patients are stratified according to disease control rate vs. progressive disease at 6 mo after SIRT. which was higher in our study than in previous studies using SIRT as salvage therapy (median, $1.8 \mathrm{GBq}$ vs. $0.33-1.55 \mathrm{GBq}$, respectively) $(8-11,13)$. Indeed, in the absence of previous hepatic treatment in our patients, no dose reduction was deemed necessary, as opposed to when SIRT was used as salvage therapy $(9,13)$. Importantly, observed adverse events in our study were self-limited and either asymptomatic or managed conservatively.

Our study included a thorough analysis of size-based (WHO/RECIST) and enhancementbased (mRECIST/EASL) criteria. WHO and RECIST categorized most patients as nonresponders after SIRT and were unable to predict survival. However, with enhancementbased criteria, at 3 mo after therapy for EASL and at 6 mo for both mRECIST and EASL, an accurate survival prediction could be done (a trend was observed at 3 mo for mRECIST, $P=0.052)$. Taken together, these results show, as demonstrated previously $(20,25,26)$, that response criteria assessing tumor viability (i.e., enhancement) outperform response criteria assessing tumor size, in terms of ability not only to correctly distinguish responders from nonresponders but also to do it earlier. These results also show that response to therapy may be delayed and that some patients who do not respond early after SIRT may still exhibit a response at 6 mo. Published reports in a salvage setting used RECIST (also WHO/EASL (11)) $(8-14,27)$. Our results for disease control rate using RECIST compare favorably with use of SIRT as salvage therapy at 3 mo ( $84 \%$ vs. $43 \%-78 \%)$ $(10,12,13)$. With mRECIST or EASL, the disease control rate at 3 mo was $92 \%$ and $87.5 \%$, respectively. The interval between SIRT and radiologic response evaluation was not clearly mentioned in the other studies $(8,9,11,14)$, and two of them also reported ocular, cutaneous, and other melanomas $(11,14)$, which makes any comparison hazardous.

Median OSs ranging from 3.1 to 12.3 mo have been obtained in previous studies about SIRT used as salvage therapy (8-14). Consequently, our results are promising, with a median OS of 18 mo $(95 \%$ CI, 8-28 mo) after first-line SIRT, and are similar to a recently published small cohort of uveal melanoma patients also treated with firstline SIRT (27). At the end of our follow-up period, 5 patients $(23 \%)$ were still alive, underlining the fact that reported outcomes might improve still further. Our survival time was longer than the 14.9 mo estimated by a prognostic model with the most favorable parameters (i.e., high Karnofsky index, low dimension of the largest metastasis, and low alkaline phosphatase level) (28). Our results are also encouraging in light of the fact that patients treated with first-line SIRT may have good or aggressive cancer biology, whereas when salvage SIRT is used, some patients with aggressive disease and initially treated with, for example, systemic chemotherapy, will die before undergoing salvage SIRT whereas other patients will have hepatic disease progression precluding SIRT. Such patients would not be captured in the salvage SIRT studies (patient selection bias). Importantly, the median hepatic progression-free survival of $8 \mathrm{mo}(95 \% \mathrm{CI}$, 5-26 mo) also compares favorably with the 4.2-5.9 mo found in previous studies $(9-11,14)$. Collectively, these results confirm the radiosensitivity of uveal melanoma metastatic to the liver and highlight the ability of SIRT to effectively control liver disease. The absence of 
TABLE 4

OS

\begin{tabular}{|c|c|c|c|c|}
\hline \multirow[b]{2}{*}{ Parameter } & \multicolumn{2}{|c|}{ Univariate analysis } & \multicolumn{2}{|c|}{ Multivariate analysis } \\
\hline & $\mathrm{HR}$ & $P$ & $\mathrm{HR}$ & $P$ \\
\hline Sex & $1.22(0.47-3.17)$ & 0.68 & - & - \\
\hline Age & $1.03(0.99-1.07)$ & 0.1003 & - & - \\
\hline ECOG status & $2.73(0.88-8.44)$ & 0.08 & $1.85(0.47-7.24)$ & 0.38 \\
\hline Primary tumor treatment (surgery vs. proton therapy) & $1.22(0.39-3.84)$ & 0.74 & - & - \\
\hline Time between eye tumor diagnosis and metastasis & $0.99(0.97-1.00)$ & 0.12 & - & - \\
\hline Time between metastasis diagnosis and SIRT & $0.89(0.50-1.61)$ & 0.72 & - & - \\
\hline Largest lesion $(\mathrm{cm})$ & $1.30(1.08-1.57)$ & 0.005 & $1.22(0.98-1.53)$ & 0.08 \\
\hline Estimated number of lesions & $1.28(0.48-3.45)$ & 0.62 & - & - \\
\hline Metastasis distribution (unilobar/bilobar) & $1.41(0.32-6.22)$ & 0.65 & - & - \\
\hline Baseline $\mathrm{SUV}_{\max }$ & $1.02(0.91-1.15)$ & 0.72 & - & - \\
\hline Extrahepatic metastases before SIRT & $1.21(0.34-4.29)$ & 0.77 & - & - \\
\hline${ }^{90}$ Y-microspheres (SIR-Spheres vs. TheraSphere) & $0.75(1.34-2.12)$ & 0.34 & - & - \\
\hline Treated tumor volume $\left(\mathrm{cm}^{3}\right)$ & $1.0008(1.0001-1.002)$ & 0.02 & $1.002(1.0004-1.003)$ & 0.007 \\
\hline Liver treated (lobar vs. whole) & $0.72(0.25-2.09)$ & 0.55 & - & - \\
\hline $\begin{array}{l}\text { Liver treated (whole in } 1 \text { session, whole in multiple } \\
\text { sessions, lobar) }\end{array}$ & $0.91(1.10-1.43)$ & 0.54 & - & - \\
\hline Number of SIRTs per patient & $1.001(0.42-2.37)$ & 0.99 & - & - \\
\hline $\begin{array}{l}\text { Mean of all SIRT session activity administered per } \\
\text { patient (GBq) }\end{array}$ & $2.54(0.96-6.73)$ & 0.06 & $-^{*}$ & - \\
\hline $\begin{array}{l}\text { Sum of all SIRT session activity administered per } \\
\text { patient (GBq) }\end{array}$ & $1.19(0.77-1.86)$ & 0.42 & - & - \\
\hline Mean dose to healthy liver (Gy) & $0.98(0.95-1.01)$ & 0.18 & - & - \\
\hline Mean dose to tumor (Gy) & $0.99(0.98-1.01)$ & 0.56 & - & - \\
\hline Tumor-to-liver uptake ratio & $1.11(0.89-1.38)$ & 0.36 & - & - \\
\hline Pulmonary shunt fraction (\%) & $0.43(0.15-1.21)$ & 0.11 & - & - \\
\hline Post-SIRT systemic therapies & $0.33(0.12-0.86)$ & 0.02 & $0.04(0.006-0.24)$ & 0.0005 \\
\hline Post-SIRT locoregional therapies & $0.21(0.07-0.62)$ & 0.005 & $0.204(0.04-0.94)$ & 0.04 \\
\hline Extrahepatic metastasis after SIRT & $0.98(0.28-3.48)$ & 0.98 & - & - \\
\hline Highest complication grade (CTCAE) & $1.37(0.86-2.18)$ & 0.19 & - & - \\
\hline \multicolumn{5}{|c|}{$\begin{array}{l}{ }^{*} \text { Omitted from multivariate analysis as it is highly correlated with treated tumor volume. } \\
\text { CTCAE = Common Terminology Criteria for Adverse Events. } \\
\text { Data in parentheses are } 95 \% \mathrm{Cl} \text {. }\end{array}$} \\
\hline
\end{tabular}

dose reduction performed in a salvage setting $(9,13)$ may potentially explain part of the increased efficacy of first-line SIRT, in view of the link between the dose and tumor response (29). Moreover, we found that tumor burden correlated negatively with survival, as is consistent with previously published data on uveal melanoma patients treated with SIRT as salvage therapy $(9,14)$. This finding sheds light on the importance of surveillance programs screening for liver metastases, since the earlier they are detected the better are the chances of providing effective treatment (28). Of note, baseline extrahepatic metastases or development of extrahepatic metastatic disease during follow-up did not correlate with survival, highlighting not only that hepatic disease control is important to survival but also that extrahepatic metastases should not be considered a contraindication to SIRT.

Subsequent liver-directed and systemic therapies performed after SIRT also correlated positively with survival. In our study, 4 patients (18\%) underwent chemoembolization and $5(23 \%)$ underwent thermal ablation. Transarterial chemoembolization has been shown to increase OS, particularly in patients with a limited tumor burden, preserved liver function, and good performance status (30). Similarly to surgery, thermal ablations were shown to be effective in cases of localized disease (31). Although most of our patients had diffuse involvement of the liver parenchyma, in some of them tumor burden was predominant in a single lobe, allowing ablation of contralateral isolated lesions. Taken together, these results show the importance of patient selection and combination therapies. Although the heterogeneity of therapies that our patient cohort received does not allow us to draw definite conclusions about a particular post-SIRT treatment, first-line SIRT not only does not preclude subsequent treatments (liver-directed and systemic) but also may have synergistic abilities, in particular with immunotherapies (32). Further studies combining first-line SIRT with systemic therapies are needed.

Strengths of this study include a comprehensive safety/toxicity, tumor response, and survival analysis of a clinically relevant scenariofirst-line SIRT in uveal melanoma patients-in a real-life setting at a comprehensive cancer center. A long follow-up was performed to provide mature data. There were several limitations to this research. First, 
it was a retrospective single-center study with a limited number of patients. However, uveal melanoma is a rare disease, and our sample size was larger than that in most published studies $(8,10-12,14,27,33)$. Moreover, our cohort comprised prospectively collected patients, because in such patients first-line SIRT is performed systematically whenever possible, leaving its use as a second-line or further treatment dependent on a patient's referral. Second, patients lost to follow-up $(3 / 25,12 \%)$ potentially might have had unrecognized outcomes. Third, the fact that most of our patients received different additional therapies after SIRT may have biased the results. However, this reflects real-life practice for a highly resistant disease with no established treatment. Fourth, post-SIRT PET/CT was not available for all patients, and functional response therefore could not be evaluated. Fifth, stratification of uveal melanoma according to genetic subtype was not available, yet information on genetic subtype is of great interest for the development of molecularly targeted therapies.

\section{CONCLUSION}

First-line SIRT is safe and produced promising outcomes in patients with uveal melanoma metastatic to the liver. Importantly, subsequent systemic and liver-directed locoregional therapies not only were possible after first-line SIRT but also improved survival, highlighting the potential for improved outcomes with combination approaches. The results of this study suggest that prospective trials using first-line SIRT should be considered.

\section{DISCLOSURE}

No potential conflict of interest relevant to this article was reported.

\section{KEY POINTS}

QUESTION: Is first-line SIRT a safe and effective option for patients with uveal melanoma metastatic to the liver?

PERTINENT FINDINGS: First-line SIRT for patients with uveal melanoma metastatic to the liver was safe and achieved promising survival outcomes. Subsequent liver-directed and systemic therapies positively influenced survival, and a combined approach therefore seems crucial. Because lower tumor burden is associated with longer survival, early detection and treatment with SIRT are essential for improved outcomes.

IMPLICATIONS FOR PATIENT CARE: First-line SIRT for patients with uveal melanoma metastatic to the liver achieves promising survival and does not preclude subsequent liver-directed and systemic therapies, highlighting that combination approaches may improve existing survival outcomes.

\section{REFERENCES}

1. Singh AD, Turell ME, Topham AK. Uveal melanoma: trends in incidence, treatment, and survival. Ophthalmology. 2011;118:1881-1885.

2. Diener-West M, Reynolds SM, Agugliaro DJ, et al. Development of metastatic disease after enrollment in the COMS trials for treatment of choroidal melanoma: Collaborative Ocular Melanoma Study Group report no. 26. Arch Ophthalmol. 2005;123:1639-1643.

3. Kujala E, Mäkitie T, Kivelä T. Very long-term prognosis of patients with malignant uveal melanoma. Invest Ophthalmol Vis Sci. 2003;44:4651-4659.

4. Lane AM, Kim IK, Gragoudas ES. Survival rates in patients after treatment for metastasis from uveal melanoma. JAMA Ophthalmol. 2018;136:981-986.

5. Yang J, Manson DK, Marr BP, Carvajal RD. Treatment of uveal melanoma: where are we now? Ther Adv Med Oncol. 2018;10:175883401875717.

6. Sato T. Locoregional management of hepatic metastasis from primary uveal melanoma. Semin Oncol. 2010;37:127-138.
7. Breedis C, Young G. The blood supply of neoplasms in the liver. Am J Pathol. 1954;30:969-977.

8. Kennedy AS, Nutting C, Jakobs T, et al. A first report of radioembolization for hepatic metastases from ocular melanoma. Cancer Invest. 2009;27:682-690.

9. Gonsalves CF, Eschelman DJ, Sullivan KL, Anne PR, Doyle L, Sato T. Radioembolization as salvage therapy for hepatic metastasis of uveal melanoma: a single-institution experience. AJR. 2011;196:468-473.

10. Klingenstein A, Haug AR, Zech CJ, Schaller UC. Radioembolization as locoregional therapy of hepatic metastases in uveal melanoma patients. Cardiovasc Intervent Radiol. 2013;36:158-165.

11. Memon K, Kuzel TM, Vouche M, Atassi R, Lewandowski RJ, Salem R. Hepatic yttrium-90 radioembolization for metastatic melanoma: a single-center experience. Melanoma Res. 2014;24:244-251.

12. Schelhorn J, Richly H, Ruhlmann M, Lauenstein TC, Theysohn JM. A singlecenter experience in radioembolization as salvage therapy of hepatic metastases of uveal melanoma. Acta Radiol Open. 2015;4:2047981615570417.

13. Eldredge-Hindy H, Ohri N, Anne PR, et al. Yttrium- 90 microsphere brachytherapy for liver metastases from uveal melanoma: clinical outcomes and the predictive value of fluorodeoxyglucose positron emission tomography. Am J Clin Oncol. 2016;39:189-195.

14. Xing M, Prajapati HJ, Dhanasekaran R, et al. Selective internal yttrium-90 radioembolization therapy $\left({ }^{90} \mathrm{Y}\right.$-SIRT) versus best supportive care in patients with unresectable metastatic melanoma to the liver refractory to systemic therapy: safety and efficacy cohort study. Am J Clin Oncol. 2017;40:27-34.

15. Kivelä TT, Piperno-Neumann S, Desjardins L, et al. Validation of a prognostic staging for metastatic uveal melanoma: a collaborative study of the European ophthalmic oncology sroup. Am J Ophthalmol. 2016;168:217-226.

16. Kennedy A, Nag S, Salem R, et al. Recommendations for radioembolization of hepatic malignancies using yttrium-90 microsphere brachytherapy: a consensus panel report from the radioembolization brachytherapy oncology consortium. Int J Radiat Oncol Biol Phys. 2007;68:13-23.

17. Denys A, Pracht M, Duran R, et al. How to prepare a patient for transarterial radioembolization? A practical guide. Cardiovasc Intervent Radiol. 2015;38:794-805.

18. Lau W-Y, Kennedy AS, Kim YH, et al. Patient selection and activity planning guide for selective internal radiotherapy with yttrium-90 resin microspheres. Int J Radiat Oncol Biol Phys. 2012;82:401-407.

19. Salem R, Thurston KG. Radioembolization with ${ }^{90}$ yttrium microspheres: a state-of-theart brachytherapy treatment for primary and secondary liver malignancies. Part 1: technical and methodologic considerations. J Vasc Interv Radiol. 2006;17:1251-1278.

20. Duran R, Chapiro J, Frangakis C, et al. Uveal melanoma metastatic to the liver: the role of quantitative volumetric contrast-enhanced MR imaging in the assessment of early tumor response after transarterial chemoembolization. Transl Oncol. 2014;7:447-455.

21. Miller AB, Hoogstraten B, Staquet M, Winkler A. Reporting results of cancer treatment. Cancer. 1981;47:207-214.

22. Eisenhauer EA, Therasse P, Bogaerts J, et al. New response evaluation criteria in solid tumours: revised RECIST guideline (version 1.1). Eur J Cancer. 2009;45:228-247.

23. Lencioni R, Llovet JM. Modified RECIST (mRECIST) assessment for hepatocellular carcinoma. Semin Liver Dis. 2010;30:52-60.

24. Bruix J, Sherman M, Llovet JM, et al. Clinical management of hepatocellular carcinoma: conclusions of the Barcelona-2000 EASL conference. European Association for the Study of the Liver. J Hepatol. 2001;35:421-430.

25. Buijs M, Vossen JA, Hong K, Georgiades CS, Geschwind J-FH, Kamel IR. Chemoembolization of hepatic metastases from ocular melanoma: assessment of response with contrast-enhanced and diffusion-weighted MRI. AJR. 2008;191:285-289.

26. Riaz A, Memon K, Miller FH, et al. Role of the EASL, RECIST, and WHO response guidelines alone or in combination for hepatocellular carcinoma: radiologicpathologic correlation. J Hepatol. 2011;54:695-704.

27. Tulokas S, Mäenpää H, Peltola E, et al. Selective internal radiation therapy (SIRT) as treatment for hepatic metastases of uveal melanoma: a Finnish nationwide retrospective experience. Acta Oncol. 2018;57:1373-1380.

28. Eskelin S, Pyrhönen S, Hahka-Kemppinen M, Tuomaala S, Kivelä T. A prognostic model and staging for metastatic uveal melanoma. Cancer. 2003;97:465-475.

29. Garin E, Rolland Y, Edeline J, et al. Personalized dosimetry with intensification using ${ }^{90} \mathrm{Y}$-loaded glass microsphere radioembolization induces prolonged overall survival in hepatocellular carcinoma patients with portal vein thrombosis. $J$ Nucl Med. 2015;56:339-346.

30. Eschelman DJ, Gonsalves CF, Sato T. Transhepatic therapies for metastatic uveal melanoma. Semin Intervent Radiol. 2013;30:39-48.

31. Mariani P, Almubarak MM, Kollen M, et al. Radiofrequency ablation and surgical resection of liver metastases from uveal melanoma. Eur J Surg Oncol. 2016;42:706-712.

32. Chew V, Lee YH, Pan L, et al. Immune activation underlies a sustained clinical response to yttrium-90 radioembolisation in hepatocellular carcinoma. Gut. 2019;68:335-346.

33. Abbott AM, Doepker MP, Kim Y, et al. Hepatic progression-free and overall survival after regional therapy to the liver for metastatic melanoma. Am J Clin Oncol. 2018;41:747-753. 